\title{
Evaluation of the Effect of Patient Preparation Using Castor Oil on ADC Value of Focal Liver Lesion
}

This article was published in the following Dove Press journal: International Journal of General Medicine

\section{Kawa Abdulla Mahmood (D) Rezheen Jamal Rashid (iD Salah Mohammed Fateh Naser Abdullah Mohammed \\ University of Sulaimani, College of Medicine, Department of Surgery- Diagnostic Imaging Unit, Sulaymaniyah, Kurdistan Region, Iraq}

Correspondence: Kawa Abdulla Mahmood

Tel +9647701545538

Email kawa.mahmood@univsul.edu.iq
Purpose: To estimate the role of patient preparation using castor oil on the ADC value of focal liver lesion.

Patients and Methods: Retrospective case-control study over more than two years. Magnetic resonance imaging (MRI) scan, including diffusion-weighted imaging (DWI) of the upper abdomen performed for 87 cases and 71 controls in patients with focal hepatic hemangiomas. Cases were prepared using castor oil prior to the scan without identifiable unwanted effect, while controls did not receive any special preparation. Since liver hemangioma is a common lesion, it was selected and used as a sample. Apparent Diffusion Coefficient (ADC) values of focal liver lesion were calculated in cases and controls.

Results: The mean ADC value of liver hemangioma was lower in cases compared to controls; the mean ADC value was $\left(2.21 \pm 0.39 \times 10^{-3} \mathrm{~mm}^{2} / \mathrm{s}\right)$ in cases and $(2.51$ $\left.\pm 0.49 \times 10^{-3} \mathrm{~mm}^{2} / \mathrm{s}\right)$ in controls. Left lobes were more affected by lesions; the mean ADC value of the left lobe lesions was $\left(2.26 \pm 0.37 \times 10^{-3} \mathrm{~mm}^{2} / \mathrm{s}\right)$ and $\left(2.86 \pm 0.43 \times 10^{-3} \mathrm{~mm}^{2} / \mathrm{s}\right)$ in cases and controls, respectively. The ADC value of lesions in the right lobe was $(2.19$ $\left.\pm 0.39 \times 10^{-3} \mathrm{~mm}^{2} / \mathrm{s}\right)$ in cases and $\left(2.39 \pm 0.45 \times 10^{-3} \mathrm{~mm}^{2} / \mathrm{s}\right)$ in controls. There was a significant segmental ADC variation; lesions at segments II, III, IVb, and V demonstrated illusive ADC elevation in controls.

Conclusion: There is erroneous elevation of lobar and segmental ADC value of liver hemangiomas in non prepared patients. This Potential source of error (peristalsis, partial volume, and paramagnetic gas effect of gastrointestinal tract) on hepatic lesions' ADC value can be avoided by proper preparation using castor oil prior to MRI scanning.

Keywords: liver hemangioma, apparent diffusion coefficient value, patient preparation, castor oil

\section{Introduction}

Since its introduction, MRI has been an attractive imaging modality for different body parts due to its detailed functional information and lack of ionizing radiation, particularly for liver imaging. Based on the Brownian motion of water molecules due to thermal agitation, diffusion is a reliable imaging method for tissue characterization. Performing diffusion-weighted imaging (DWI) on liver examination allows quantitative characterization of liver lesions. The MR software automatically produces an apparent diffusion coefficient (ADC) Map. ${ }^{1-7}$

Nowadays, MRI is the modality of choice for liver lesions detection and characterization, and the DWI sequence is used as a biomarker due to its role at 
the molecular level. The diagnostic confusion among various liver lesions can be reduced using ADC value measuring that may add information about the pathological process. $^{8-12}$

Several factors affects on ADC value variability as vendor characteristics, magnetic field strength, different diffusion-weighted images protocol, different $\mathrm{b}$ values, software platform, gastrointestinal intraluminal content and peristalsis, liver steatosis, liver parenchymal disease, metabolic liver disease, lesion size and location, intralesional complication as hemorrhage, inflammation or thrombosis, and age-related variation. ${ }^{1,2,4,5,13-23}$

Among the hepatic lesions, hemangioma is the most common lesion in about $20 \%$ of the general population, and its atypical presentation is not uncommon. MRI is regarded as a reliable tool for diagnosis with a high accuracy rate. ${ }^{10,24}$

Oral administration of castor oil before the MRI scan has to affect empty the stomach and bowel due to its laxative effect and improving image quality. Bowel preparation is regarded as necessary prior to radiological examinations of the abdominal region. ${ }^{25-28}$ Oral intake of castor oil might induce nausea; otherwise, it is generally recognized and classified as safe and effective for use as a stimulant laxative. ${ }^{29,30}$

\section{Objective}

This study aims to estimate the role of patient preparation using castor oil on the ADC value of focal liver lesion.

\section{Patients and Methods}

MRI scan of the upper abdomen was carried out for 158 patients with age 18-60 years from May 2018 till July 2020 at Hiwa Cancer Hospital. This study was conducted in accordance with the Declaration of Helsinki. Formal ethical approval was obtained from the local ethical committee -University of Sulaimani/College of Medicine, after hospital authentication informed consents were obtained from all patients.

Only patients with particular liver lesions were included: Patients with typical hemangioma that fulfills radiological criteria (hypointense on T1-weighted images, homogenous and hyperintense on T2-weighted images "similar to cerebrospinal fluid", absence of restriction on DWI, and slow enhancement kinetics, in the form of peripheral nodular enhancement, progressive, centripetal, late, full and persistent filling). ${ }^{19,24,31}$ Only hemangiomas ranging from 10 to $50 \mathrm{~mm}$ were included.
Our sample size was 220 patients. We excluded those with atypical hemangioma, parenchymal liver disease, ages below 18 and above 60 years, and patients who received chemotherapy. The number of included patients was 158 patients, while 62 patients were excluded among the cases and controls.

We retrospectively categorized the patients into two groups; group one (cases or prepared patients) and group two (controls or non-prepared patients). Group one consisted of 87 prepared patients who received castor oil before the MRI study and group two (71 non-prepared patients) who refused to receive the castor oil.

The cases were prepared by drinking $50 \mathrm{~mL}$ of castor oil (Oleum Palmae Christi) on the day before the exam to purge the bowel and reduce the motion artifact from distorting paramagnetic gas and partial volume of gastrointestinal content on focal liver lesions' ADC value. In contrast, the control group did not receive any special preparation. No identifiable unwanted effect were recorded.

Patients underwent an MRI scan of the upper abdomen for different purposes. Patients were scanned using the same MRI scanner (MAGNETOM Aera 1.5Tesla) and the same MRI protocol. Cardiac and respiratory-triggered axial DWI $\left(b=50\right.$ and $b=800 \mathrm{~s} / \mathrm{mm}^{2}$ ) was obtained. ADC map was generated by the MR scanner using the $b$ values systematically. In addition to the DWI, other sequences were obtained as part of MRI scanning, as shown in Table 1.

A round region of interest (ROI) was manually drawn, covering most of the lesion. Dedicated workstation (Hp server-based workstation, syngo.via Version: VB10B) used for ADC analysis. Three expert radiologists who were blinded to the bowel preparation plan (with 18, 13, and 9 years of experience in abdominal imaging) reviewed the ADC map. The statistical analysis was performed using

Table I MRI Sequences

\begin{tabular}{|l|l|}
\hline \multicolumn{2}{|l|}{ MRI Sequences and Parameters } \\
\hline Axial T2 haste fat suppression & (TR/TE: 1000/93ms) \\
Coronal and axial T2 haste & (TR/TE: 1000/89ms) \\
Axial dual opposed-phase TIWI & (in phase TR/TE:6.8/4.8, out phase \\
vibe Dixon & TR/TE: 6.8/2.4ms) \\
Axial and coronal pre-contrast & (TR/TE: 6.8/4.8ms) \\
TIWI vibe Dixon & \\
Axial pre and post contrast & (TR/TE: $4.8 / 2.3 \mathrm{~ms})$ \\
TIfat suppression vibe & \\
\hline
\end{tabular}


SPSS version 21.0 (Student's $t$-test was used to calculate the mean values, and 0.05 was considered as cut-off point for statistical significance). The data supporting this study is uploaded in the form of Excel sheet file which contains data about age and gender of the patients, also number and size of the lesions, as well as ADC value of hemangioma in both cases and controls at different liver segments.

\section{Results}

A total of 158 patients with 235 liver hemangiomas (87 cases with 123 liver lesions and 71 controls with 112 liver lesions) included, the age ranges from 18 to 60 years (mean age $41.1 \pm 11.8$ ), and (female to male ratio 2.2:1). Multiple hemangiomas were present in 41 patients, 18 patients $(11.3 \%)$ had two hemangiomas, 3 lesions, 4 lesions, 5 lesions found in $13(8.2 \%), 7(4.5 \%)$, and 3 (1.8\%) patients, respectively, $173(73.6 \%)$ lesions were in Rt. Lobe and 62 (26.4\%) lesions in the left lobe.

The mean ADC value of liver hemangioma was lower in cases versus control patients. The mean ADC value of liver hemangioma at both lobes was affected by preparation to a variable degree, as shown in Table 2 .

Table 2 ADC Value of the Left Lobe Compared to the Right Lobe Hemangiomas

\begin{tabular}{|l|l|l|l|}
\hline \multirow{2}{*}{} & \multicolumn{2}{|l|}{$\begin{array}{l}\text { Mean ADC Value of } \\
\text { Hemangioma }\left(\times 10^{-3} \mathrm{~mm}^{2} / \mathbf{s}\right)\end{array}$} & \multirow{2}{*}{ P value } \\
\cline { 2 - 3 } & Case & Control & \\
\hline Liver lesion & $2.21 \pm 0.39$ & $2.51 \pm 0.49$ & $<0.0001$ \\
Right lobe lesion & $2.19 \pm 0.39$ & $2.39 \pm 0.45$ & 0.0021 \\
Left Lobe lesion & $2.26 \pm 0.37$ & $2.86 \pm 0.43$ & $<0.0001$ \\
\hline
\end{tabular}

There was a segmental hemangioma ADC variation of prepared versus non-prepared subjects; lesions at segments II, III, IVb, and V were significantly affected by GIT content, as summarized in Table 3.

\section{Discussion}

Different liver lesions showed variable ADC values. ${ }^{4,5}$ In our analysis, we selected and used liver hemangioma as a sample to assess the effect of patient preparation on $\mathrm{ADC}$ value since hemangioma is a common lesion (up to $20 \%$ of the general population), and it tends to subcapsular and peripheral location. ${ }^{10,31,32}$

Focal liver lesion ADC value is influenced by many factors as hardware and software variability, diffusion protocol, gastrointestinal content and peristalsis, chemotherapy drugs, fatty liver disease, liver parenchymal disease, metabolic liver disease, lesion size and location, intra-lesional complication as hemorrhage, inflammation or thrombosis, age-related variation. ${ }^{1,2,4,5,13-23}$

After controlling the mentioned factors' effects via scanning all patients with the same MR scanner and using the same MR imaging protocol, excluding patients on chemotherapy, diffuse liver disease, lesion complication, and eliminating aging factor, we observed the impact of gastrointestinal content solely on ADC variance of liver hemangioma (Table 2).

Typically, liver hemangioma appeared hyper intense on T2WI (Figure 1A) and not restricted on $\mathrm{DWI}^{2}$ (as shown in Figure 1B-D). The mean ADC values were lower in cases (Figure 1A-D) compared to controls. This significant false ADC value elevation ( $p$-value $<0.0001$ ) in controls is related to GIT content and its associated partial volume effect from bowel peristalsis.

Table 3 The Number and the Mean ADC Values of Hemangiomas in Cases and Controls at Different Hepatic Segments

\begin{tabular}{|c|c|c|c|c|c|}
\hline \multirow{2}{*}{$\begin{array}{l}\text { Liver } \\
\text { Segments }\end{array}$} & \multicolumn{2}{|l|}{ Cases } & \multicolumn{2}{|l|}{ Controls } & \multirow[t]{2}{*}{ P-value } \\
\hline & $\begin{array}{l}\text { No. of } \\
\text { Hemangioma }\end{array}$ & $\begin{array}{l}\text { Mean ADC Value } \\
\left(\times 10^{-3} \mathrm{~mm}^{2} / \mathrm{s}\right)\end{array}$ & $\begin{array}{l}\text { No. of } \\
\text { Hemangioma }\end{array}$ & $\begin{array}{l}\text { Mean ADC Value } \\
\left(\times 10^{-3} \mathrm{~mm}^{2} / \mathrm{s}\right)\end{array}$ & \\
\hline Segment I & 0 & - & I & 1.98 & - \\
\hline Segment II & 16 & $2.42 \pm 0.27$ & 13 & $2.91 \pm 0.5$ & 0.0023 \\
\hline Segment III & 19 & $2.13 \pm 0.4$ & 14 & $2.82 \pm 0.34$ & 0.0002 \\
\hline Segment IVa & 18 & $2.24 \pm 0.38$ & 16 & $2.4 \pm 2.43$ & 0.2578 \\
\hline Segment IVb & 11 & $2.18 \pm 0.37$ & 11 & $2.65 \pm 0.49$ & 0.0195 \\
\hline Segment V & 12 & $2.04 \pm 0.36$ & 15 & $2.43 \pm 0.39$ & 0.0131 \\
\hline Segment VI & 13 & $2.27 \pm 0.35$ & II & $2.51 \pm 0.5$ & 0.1817 \\
\hline Segment VII & 19 & $2.22 \pm 0.4$ & 14 & $2.39 \pm 0.33$ & 0.2043 \\
\hline Segment VIII & 15 & $2.16 \pm 0.42$ & 17 & $2.14 \pm 0.4$ & 0.8913 \\
\hline
\end{tabular}


A

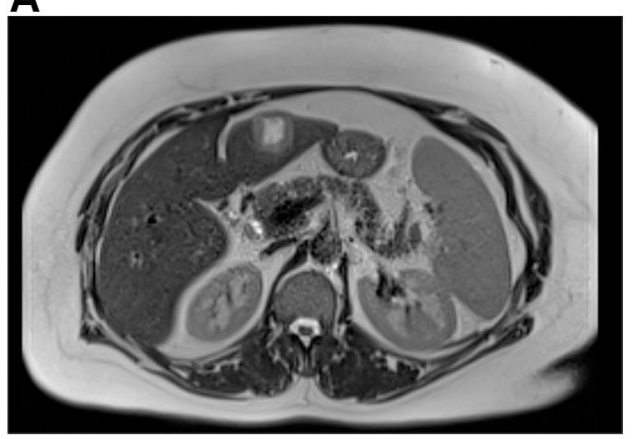

C

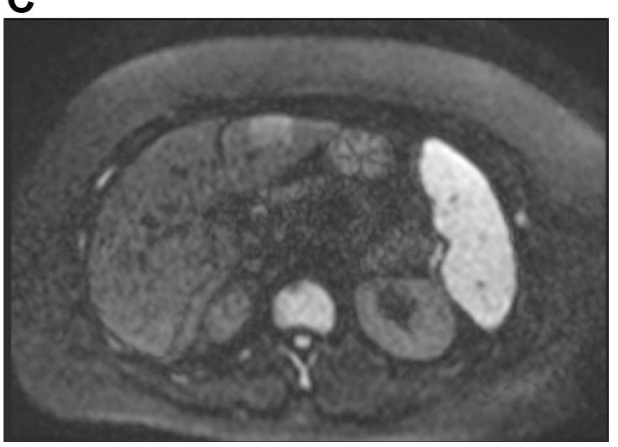

B

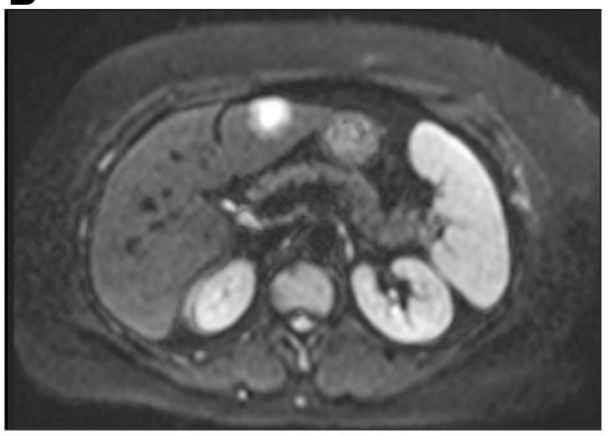

D

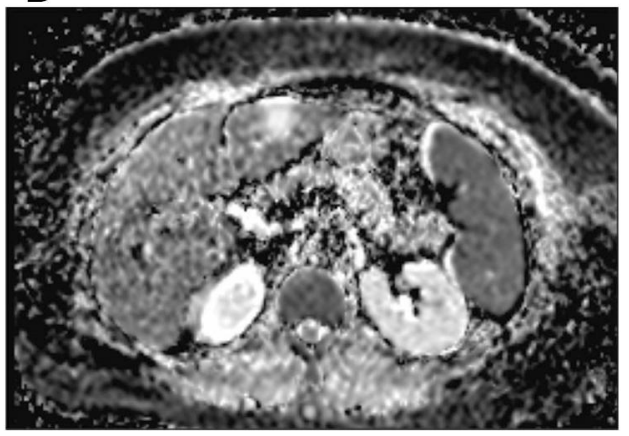

Figure I MRI scan displaying segment II subcapsular typical liver hemangioma in a 48-years old case (prepared with castor oil). (A) The lesion is hyperintense on T2WI. (B) The hemangioma is hyperintense at $b$ value $50 \mathrm{~mm}^{2} / \mathrm{s}$, whereas (C) moderately hyperintense at b values $800 \mathrm{~mm}^{2} / \mathrm{s}$. (D) The quantitative ADC data of the lesion is $(2.108 \pm$ $\left.0.13 \times 10^{-3} \mathrm{~mm}^{2} / \mathrm{s}\right)$.

A

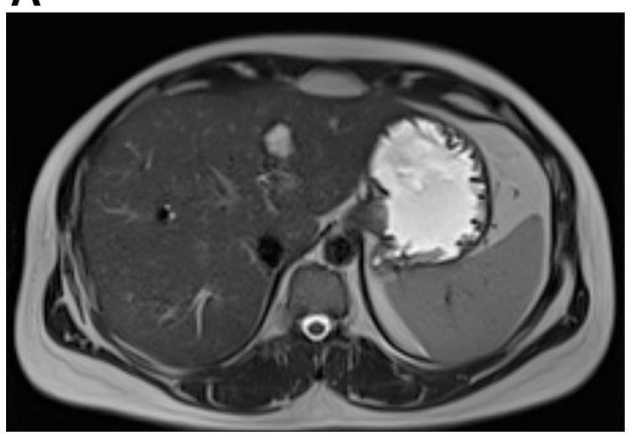

C

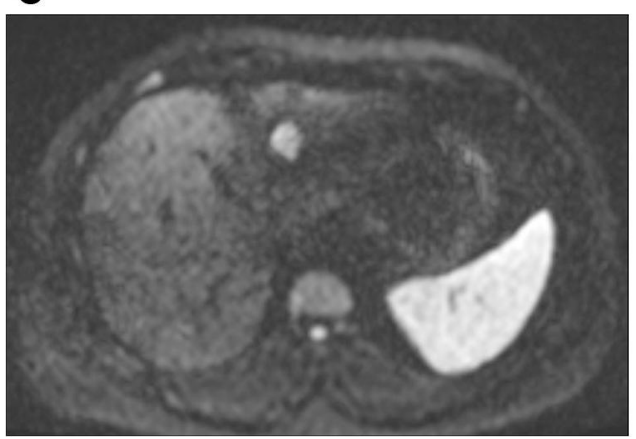

B

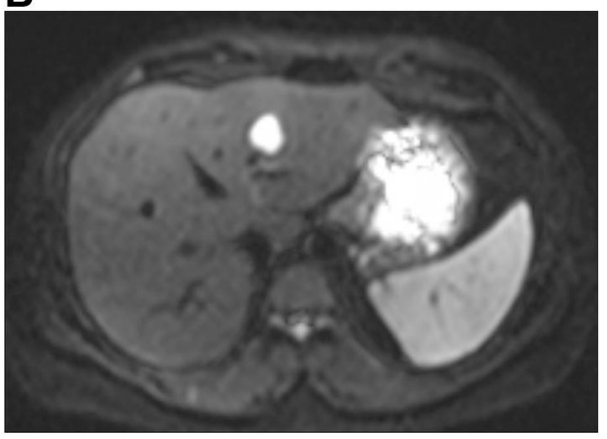

D

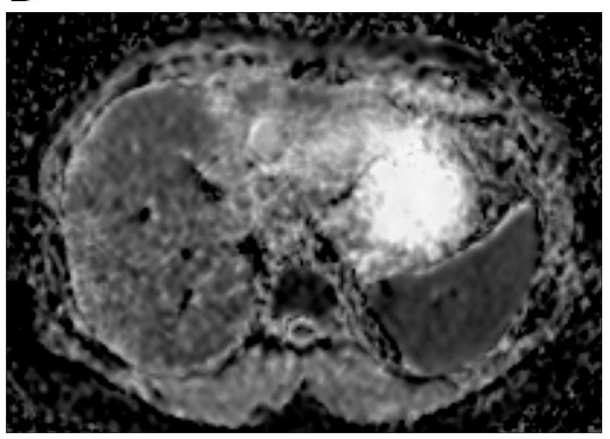

Figure 2 MRI is demonstrating segment II typical liver hemangioma in a 43-years non-prepared patient. (A) The hemangioma is homogenously hyperintense on T2WI. (B and C) The lesion is demonstrating variable high signal intensity on DWl at b values 50 and $800 \mathrm{~mm}^{2} / \mathrm{s}$, respectively. (D) On the ADC map, the lesion's ADC value is $\left(2.397 \pm 0.48 \times 10^{-3} \mathrm{~mm}^{2} / \mathrm{s}\right)$. 
The mean ADC value of liver hemangioma was significantly different; $\left(2.21 \pm 0.39 \times 10^{-3} \mathrm{~mm}^{2} / \mathrm{s}\right)$ in cases while $\left(2.51 \pm 0.49 \times 10^{-3} \mathrm{~mm}^{2} / \mathrm{s}\right)$ in controls. There is also lobar ADC variation; left lobe lesions were more affected by the GIT content, mean ADC value was $\left(2.26 \pm 0.37 \times 10^{-3} \mathrm{~mm}^{2} / \mathrm{s}\right)$ in cases and $(2.86$ $\pm 0.43 \times 10^{-3} \mathrm{~mm}^{2} / \mathrm{s}$ ) in control subjects compared to Right lobe lesions $\left(2.19 \pm 0.39 \times 10^{-3} \mathrm{~mm}^{2} / \mathrm{s}\right)$ and $(2.39$ $\pm 0.45 \times 10^{-3} \mathrm{~mm}^{2} / \mathrm{s}$ ) in cases and controls, respectively. In our dataset, illusive ADC value elevation of liver lesions in controls (Figure 2A-D) denoted that GIT content negatively affected on ADC value of liver lesions. This concept was advocated by previous authors who referred that left lobe lesions showed deceptively elevated ADC value due to peristalsis, distorting gas, and partial volume effects of adjacent organs. ${ }^{6,18,23,33}$ Up to our knowledge, no previous study documented the difference quantitatively.

In addition to lobar ADC differences, we calculated the hepatic segmental ADC value mismatches in both groups (Table 3). Moreover, ADC values among the controls were significantly higher at segments II (Figure $1 \mathrm{~A}$ and Figure 2D), III, IVb, and $\mathrm{V}$ than in the cases, which can be explained by their proximity to the gastrointestinal tract. Comparison of ADC value of lesions at segment I was not possible since we had a single hemangioma in group two.

Unlike respiration and cardiac pulsation, which notably affect the left lobe ADC scales, ${ }^{6,18,19,23,34}$ gastric and bowel content also affects right lobe lesions, we came to the conclusion that good preparation reduced evitable potential source of error in ADC measurement of liver lesions from gastric and bowel content even if located at liver periphery near the GIT content.

\section{Conclusion}

There is erroneous elevation of lobar and segmental ADC value of liver lesions in non prepared patients. This Potential source of error (peristalsis, partial volume, and paramagnetic gas effect of gastrointestinal content) on hepatic lesions' ADC value can be diminished by proper preparation using castor oil prior to MRI scanning.

\section{Abbreviation}

GIT, gastrointestinal content; MRI, magnetic resonance imaging; DWI, diffusion-weighted imaging; ADC, apparent diffusion coefficient; T2WI, T2 weighted-image.

\section{Acknowledgments}

On behalf of all authors, I would like to extend my sincere thanks and appreciation for Staff in Hiwa Cancer Hospital who have contributed to the successfulness of this study.

\section{Disclosure}

The authors report no conflicts of interest in this work. None of the authors have financial or personal relationship with other people or organizations that could inappropriately influence or bias the content of the paper.

\section{References}

1. Pankaj Jain T, Kan TW, Edward S, Fernon H, Kansan Naider R. Evaluation of $\mathrm{ADC}$ (ratio) on liver MRI diffusion to discriminate benign versus malignant solid liver lesions. Eur J Radiol Open. 2018;5:209-214. doi:10.1016/j.ejro.2018.10.002

2. Gelebek Yilmaz F, Yildirim AE. Relative contribution of Apparent Diffusion Coefficient (ADC) values and ADC ratios of focal hepatic lesions in the characterization of benign and malignant lesions. Eur $J$ Ther. 2018;24(3):150-157. doi:10.5152/EurJTher.2018.438

3. Bharwani N, Koh DM. Diffusion-weighted imaging of the liver: an update. Cancer Imaging. 2013;13(2):171-185. doi:10.1102/14707330.2013 .0019

4. Cieszanowski A, Anysz-Grodzicka A, Szeszkowski W, et al. Characterization of focal liver lesions using quantitative techniques: comparison of apparent diffusion coefficient values and T2 relaxation times. Eur Radiol. 2012;22(11):2514-2524. doi:10.1007/s00330-0122519-x

5. Kaya B, Koc Z. Diffusion-weighted MRI and optimal b-value for characterization of liver lesions. Acta Radiol. 2014;55(5):532-542. doi: $10.1177 / 0284185113502017$

6. Taouli B, Koh D-M. Diffusion-weighted MR imaging of the liver. Radiology. 2010;254(1):47-66. doi:10.1148/radiol.09090021

7. Namimoto T, Nakagawa M, Kizaki Y, et al. Characterization of liver tumors by diffusion-weighted imaging: comparison of diagnostic performance using the mean and minimum apparent diffusion coefficient. J Comput Assist Tomogr. 2015;39(4):453-461. doi:10. 1097/RCT.0000000000000228

8. Jahic E, Sofic A, Selimovic AH. DWI/ADC in differentiation of benign from malignant focal liver lesion. Acta Informatica Medica. 2016;24(4):244-247. doi:10.5455/aim.2016.24.244-247

9. Testa ML, Chojniak R, Sene LS, et al. Is DWI/ADC a useful tool in the characterization of focal hepatic lesions suspected of malignancy? PLoS One. 2014;9(7):1-5. doi:10.1371/journal.pone.0101944

10. Vilgrain V, Boulos L, Vullierme MP, Denys A, Terris B, Menu Y. Imaging of atypical hemangiomas of the liver with pathologic correlation. Radiographics. 2000;20(2):379-397. doi:10.1148/radiographics.20.2.g00mc01379

11. Tokgoz O, Unlu E, Unal I, et al. Diagnostic value of diffusion weighted MRI and ADC in differential diagnosis of cavernous hemangioma of the liver. African Health Sciences. 2016;16:227-233. doi:10.4314/ahs.v16i1.30

12. Schmeel FC. Variability in quantitative diffusion-weighted MR imaging (DWI) across different scanners and imaging sites: is there a potential consensus that can help reducing the limits of expected bias? Eur Radiol. 2019;29(5):2243-2245. doi:10.1007/s00330-018-5866-4

13. Girometti R, Furlan A, Esposito G, et al. Relevance of b-values in evaluating liver fibrosis: a study in healthy and cirrhotic subjects using two single-shot spin-echo echo-planar diffusion-weighted sequences. J Magn Reson Imaging. 2008;28(2):411-419. doi:10.10 02/jmri.21461 
14. Inan N, Kilinc F, Sarisoy T, Gumustas S, Akansel G, Demirci A. Diffusion weighted MR imaging in the differential diagnosis of haemangiomas and metastases of the liver. Radiol Oncol. 2010;44 (1). doi:10.2478/v10019-010-0001-4

15. Kim T, Murakami T, Takahashi S, Hori M, Tsuda K, Nakamura H. Diffusion-weighted single-shot echoplanar MR imaging for liver disease. AJR Am J Roentgenol. 1999;173(2):393-398. doi:10.2214/ ajr.173.2.10430143

16. Sasaki M, Yamada K, Watanabe Y, et al. Variability in absolute apparent diffusion coefficient values across different platforms may be substantial: a multivendor, multi-institutional comparison study. Radiology. 2008;249(2):624-630. doi:10.1148/radiol.249207 1681

17. Peña-Nogales Ó, Hernando D, Aja-Fernández S, Luis-Garcia R. Determination of optimized set of b-values for apparent diffusion coefficient mapping in liver diffusion-weighted MRI. J Magn Reson. 2020;310:106634. doi:10.1016/j.jmr.2019.106634

18. Mürtz P, Flacke S, Träber F, van den Brink JS, Gieseke J, Schild HH. Abdomen: diffusion-weighted MR imaging with pulse-triggered single-shot sequences. Radiology. 2002;224(1):258-264. doi:10.11 48/radiol.2241011117

19. Bruegel M, Holzapfel K, Gaa J, et al. Characterization of focal liver lesions by ADC measurements using a respiratory triggered diffusion-weighted single-shot echo-planar MR imaging technique. Eur Radiol. 2008;18(3):477-485. doi:10.1007/s00330007-0785-9

20. Scurr ED, Collins DJ, Temple L, Karanjia N, Leach MO, Koh D-M. Appearances of colorectal hepatic metastases at diffusion-weighted MRI compared with histopathology: initial observations. Br J Radiol. 2012;85(1011):225-230. doi:10.1259/ bjr/11597735

21. Qayyum A. Diffusion-weighted imaging in the abdomen and pelvis: concepts and applications. RadioGraphics. 2009;29(6):1797-1810. doi:10.1148/rg.296095521

22. Parikh T, Drew SJ, Lee VS, et al. Focal liver lesion detection and characterization with diffusion-weighted MR imaging: comparison with standard breath-hold T2-weighted imaging. Radiology. 2008;246(3):812-822. doi:10.1148/radiol.2463070432

23. Galea N, Cantisani V, Taouli B. Liver lesion detection and characterization: role of diffusion-weighted imaging. J Magn Reson Imaging. 2013;37(6):1260-1276. doi:10.1002/jmri.23947
24. Klotz T, Montoriol P, Ines D, Petitcolin V, Joubert-zakeyh J, Garcier J. Hepatic haemangioma: common and uncommon imaging features. Diagn Interv Imaging. 2013;94(9):849-859. doi:10.1016/j. diii.2013.04.008

25. Coskun M, Mehralivand S, Shih JH, et al. Impact of bowel preparation with Fleet's ${ }^{\mathrm{TM}}$ enema on prostate MRI quality. Abdom Radiol. 2020;45(12):4252-4259. doi:10.1007/s00261-020-02487-6

26. Dai M, Zhang T, Li Q, et al. The bowel preparation for magnetic resonance enterography in patients with Crohn's disease: study protocol for a randomized controlled trial. Trials. 2019;20(1):1. doi:10.1186/s13063-018-3101-X

27. Ghazikhanlou Sani K, Jafari M-R, Shams S. A comparison of the efficacy, adverse effects, and patient compliance of the sena-graph ${ }^{\circledR}$ syrup and castor oil regimens for bowel preparation. Iran J Pharm Res. 2010;9(2):193-198.

28. Burdock GA, Carabin IG, Griffiths JC. Toxicology and pharmacology of sodium ricinoleate. Food Chem Toxicol. 2006;44(10): 1689-1698. doi:10.1016/j.fct.2006.05.007

29. Johnson W. Final report on the safety assessment of Ricinus communis (castor) seed oil, hydrogenated castor oil, glyceryl ricinoleate, glyceryl ricinoleate $\mathrm{SE}$, ricinoleic acid, potassium ricinoleate, sodium ricinoleate, zinc ricinoleate, cetyl ricinoleate, ethyl ricinoleate, glycol ricinoleate, isopropyl ricinoleate, methyl ricinoleate, and octyldodecyl ricinoleate1. Int J Toxicol. 2007;26(Suppl 3):31-77. doi:10.1080/ 10915810701663150

30. Alookaran J, Tripp J. Castor Oil. Treasure Island (FL); 2020.

31. Mamone G, Di Piazza A, Carollo V, et al. Imaging of hepatic hemangioma: from A to Z. Abdom Radiol (New York). 2020;45 (3):672-691.

32. Caseiro-Alves F, Brito J, Araujo AE, et al. Liver haemangioma: common and uncommon findings and how to improve the differential diagnosis. Eur Radiol. 2007;17(6):1544-1554. doi:10.1007/s00330006-0503-Z

33. Luo M, Zhang L, Jiang X, Zhang W-D. Intravoxel incoherent motion diffusion-weighted imaging: evaluation of the differentiation of solid hepatic lesions. Transl Oncol. 2017;10(5):831-838. doi:10.1016/j. tranon.2017.08.003

34. Koh D-M, Collins DJ. Diffusion-weighted MRI in the body: applications and challenges in oncology. AJR Am J Roentgenol. 2007;188 (6):1622-1635. doi:10.2214/AJR.06.1403
International Journal of General Medicine

\section{Publish your work in this journal}

The International Journal of General Medicine is an international, peer-reviewed open-access journal that focuses on general and internal medicine, pathogenesis, epidemiology, diagnosis, monitoring and treatment protocols. The journal is characterized by the rapid reporting of reviews, original research and clinical studies across all disease areas. The manuscript management system is completely online and includes a very quick and fair peer-review system, which is all easy to use. Visit http://www.dovepress.com/ testimonials.php to read real quotes from published authors. 